\section{OP0022 TNFI AND TOFACITINIB MONOTHERAPY AND COMPARATIVE EFFECTIVENESS IN CLINICAL PRACTICE: RESULTS FROM CORRONA REGISTRY}

G.W. Reed ${ }^{1,2}$, R.A. Gerber ${ }^{3}$, Y. Shan ${ }^{1}$, L. Takiya ${ }^{4}$, K.J. Dandreo ${ }^{1}$, D. Gruben ${ }^{3}$ J.M. Kremer ${ }^{5}$, G.V. Wallenstein ${ }^{3},{ }^{1}$ Corrona, LLC, Southborough; ${ }^{2}$ UMass Medical School, Worcester; ${ }^{3}$ Pfizer, Inc., Groton; ${ }^{4}$ Pfizer, Inc., Collegeville; ${ }^{5}$ Albany Medical College, Albany, United States

Background: TNF inhibitors (TNFi) can be used as monotherapy (mono) or in combination (combo) with conventional DMARDS (cDMARDS). Data from randomized clinical trials and European registries suggest there is evidence of better effectiveness of TNFi combo therapy than mono. Effectiveness of TNFi mono vs combo in US clinical practice, in particular among biologic naïve and experienced patients, has not been assessed. There have also been no assessments of tofacitinib (tofa) mono vs tofa combo nor tofa mono vs TNFi combo in US clinical practice. Tofacitinib is an oral Janus kinase inhibitor for the treatment of RA.

Objectives: This study quantifies the prevalence and effectiveness of TNFi monotherapy use compared to TNFi combination therapy by line of therapy in US clinical practice. Secondary objectives were to compare tofa monotherapy use and effectiveness separately to tofa combo and to TNFi combo therapies.

Methods: RA patients initiating a TNFi (adalimumab, etanercept, infliximab, golimumab, certolizumab pegol) or tofa with a six month follow-up in Corrona US were identified. A subcohort of TNFi initiations after 11/6/2012 (market approval of tofa) were used for comparisons with tofa initiators. We defined combo therapy as TNFi or tofa used with MTX only and mono as no use of any CDMARD. The primary outcome was achieving LDA (low disease activity) or remission based on CDAl $(\leq 10)$ at 6 months. Patients switching to another biologic prior to 6 months were defined as non-responders. Secondary outcomes included modified ACR20/50/70 and mean change in CDAI. Combo and mono initiators were matched within line of therapy using a propensity score. Covariates for the model were selected if the standardized mean difference between the groups $>0.1$

Results: From 10/2001 to 8/2016 there were 7976 eligible TNFi initiations in Corrona, with $2511(31 \%)$ mono initiations. Mono by line of therapy was $21 \%$, $36 \%$ and $42 \%$ for 2 nd, 3rd and 4 th line therapy, respectively. There were 555 tofa initiations with $338(61 \%)$ mono and mono rates of $47 \%, 58 \%$ and $63 \%$ for 2nd, 3rd and 4th line therapy, respectively. In the matched populations, across outcome measures (Table 1), TNFi combo was more effective than TNFi mono in 2 nd line therapy (55.6\% LDA vs $47.1 \%$ LDA) and differences diminished with 3rd line $(43.2 \%$ vs $36.6 \%)$ and 4 th line $(32.0 \%$ vs $34.0 \%)$. Tofa combo therapy was similar to mono in the matched $3 \mathrm{rd}$ and 4 th + line populations combined ( $35.2 \%$ LDA vs $31.1 \%$ LDA). Tofa mono was similar to TNFi combo therapy in the matched 3rd and 4 th + line populations combined (33.6\% LDA vs $37.5 \%$ LDA).

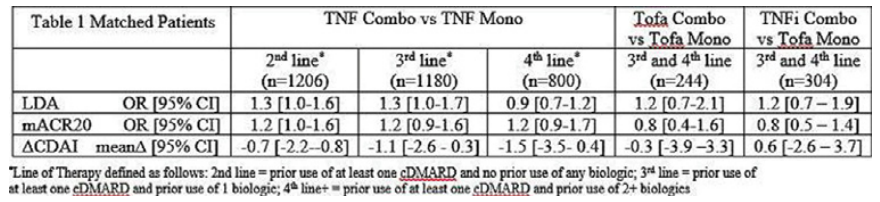

Conclusions: TNFi monotherapy is common in U.S. clinical practice. TNFi monotherapy is less effective than combination therapy especially in biologic naïve patients or with one prior biologic. There is no evidence that tofacitinib monotherapy is less effective than tofa combination therapy or TNFi combination therapy in the outcome measures reported.

Acknowledgements: This study is sponsored by Corrona, LLC. The Corrona RA registry has been supported through contracted subscriptions in the last two years by AbbVie, Amgen, Astra Zeneca, BMS, Crescendo, Eli Lilly and Company, Genentech, GSK, Horizon Pharma USA, Janssen, Momenta Pharmaceuticals, Novartis, Pfizer, Roche and UCB.

Disclosure of Interest: G. Reed Shareholder of: Corrona, LLC, Employee of: Corrona, LLC, R. Gerber Shareholder of: Pfizer, Employee of: Pfizer, Y. Shan Employee of: Corrona, LLC, L. Takiya Shareholder of: Pfizer, Employee of: Pfizer, K. Dandreo Employee of: Corrona, LLC, D. Gruben Shareholder of: Pfizer, Employee of: Pfizer, J. Kremer Shareholder of: Corrona, LLC, Grant/research support from: AbbVie, Genentech, Lilly, Novartis, Pfizer, Consultant for: AbbVie, Amgen, BMS, Genentech, Lilly, Regeneron, Sanofi, Pfizer, Employee of: Corrona, LLC, G. Wallenstein Shareholder of: Pfizer, Employee of: Pfizer DOI: 10.1136/annrheumdis-2017-eular.1939

\section{WEDNESDAY, 14 JUNE 2017 \\ Progress in managment of $\mathrm{SpA}$}

\section{OP0023 FOUR-YEAR IMAGING OUTCOMES IN AXIAL SPONDYLOARTHRITIS PATIENTS TREATED WITH CERTOLIZUMAB PEGOL, INCLUDING PATIENTS WITH ANKYLOSING SPONDYLITIS AND NON-RADIOGRAPHIC AXIAL SPONDYLOARTHRITIS}

D. van der Heijde ${ }^{1}$, X. Baraliakos ${ }^{2}$, K.G. Hermann ${ }^{3}$, R. Landewé ${ }^{4}$, P.M. Machado ${ }^{5}$, W. Maksymowych ${ }^{6}$, O. Davies ${ }^{7}$, N. de Peyrecave ${ }^{7}$ B. Hoepken ${ }^{8}$, L. Bauer ${ }^{8}$, T. Nurminen ${ }^{8}$, J. Braun ${ }^{9} .{ }^{1}$ Leiden University Medical Center, Leiden, Netherlands: ${ }^{2}$ Ruhr-University Bochum, Herne $;{ }^{3}$ Charité Medical School, Berlin, Germany; ${ }^{4}$ Academic Medical Center, Amsterdam \& Atrium Medical Center Heerlen, Amsterdam, Netherlands; ${ }^{5}$ University College London, London, United Kingdom; ${ }^{6}$ University of Alberta, Edmonton, Canada; ${ }^{7}$ UCB Pharma, Slough, United Kingdom; ${ }^{8}$ UCB Pharma, Monheim; ${ }^{9}$ Rheumazentrum Ruhrgebiet, Herne, Germany

Background: RAPID-axSpA (NCT01087762) was a long-term study in patients (pts) with axial spondyloarthritis (axSpA) treated with certolizumab pegol (CZP). This is the first report of 4-year imaging results in CZP-treated axSpA pts, including ankylosing spondylitis (AS) and non-radiographic (nr-)axSpA.

Objectives: To report 4-year X-ray and MRI data in CZP-treated axSpA pts. Methods: RAPID-axSpA ${ }^{1}$ was double-blind and placebo (PBO)-controlled to Wk24, dose-blind to Wk48, and open-label to Wk204. Pts fulfilling ASAS axSpA criteria were stratified using a local read according to presence/absence of radiographic sacroiliitis (AS/nr-axSpA) at randomization and had active disease. Wk0 CZP-randomized pts (200mg Q2W/400mg Q4W) continued assigned dose; PBO pts received CZP after Wk16/24. Centrally-read lateral X-rays of cervical/lumbar spine at baseline (BL), Wk96, and Wk204 were assessed using the modified Stoke Ankylosing Spondylitis Spinal Score (mSASSS). Sacroiliac (SI) joint X-rays were scored for sacroilitis at BL and Wk204. MRI scans performed at BL, Wks12, 48, 96, and 204 were assessed using Spondyloarthritis Research Consortium of Canada (SPARCC) score for SI joints and Berlin score for spine. Data are shown for CZP-treated pts including those starting on PBO. SI joint $\mathrm{X}$-rays (recorded at $\mathrm{BL}$ and $\mathrm{Wk204)}$ ) and magnetic resonance imaging (MRI) observed data are presented for pts with valid assessments. mSASSS data were estimated for all pts using observed data and by mixed model for repeated measures (MMRM) analysis.

Results: Of 315 CZP-treated pts, 196 had available spinal X-rays and were included in MMRM analyses (BL mean mSASSS: 9.47). 158 pts had MRI assessments (BL mean SPARCC: 8.17 [ $\mathrm{n}=151]$; Berlin score: 6.10 [n=153]) and 137 pts had SI joint X-rays at BL and Wk204 (BL: $67.9 \%$ radiographic sacroilitis). In AS pts, mean mSASSS change between BL and Wk204 was 0.98; 0.67 from BL to Wk96, and 0.31 from Wk96 to Wk204 $(0.06,-0.01$, and 0.07 respectively for nr-axSpA) (Table A). MMRM estimates were similar to observed values $(0.62$ and 0.70 , respectively [axSpA Wk204 mean change]). Limited changes in SI joint X-ray grading were observed to Wk204: only $4.5 \%$ of pts progressed to AS, whilst $4.3 \%$ moved from an AS classification to nr-axSpA. MRI assessments showed sustained improvement (Table B).

Table A: Mixed model for repeated measures (MMRM) estimates of mSASSS to Week 204 of the RAPID-axSpA study for all patients treated with CZP

\begin{tabular}{|c|c|c|c|c|c|}
\hline & \multirow{2}{*}{$\begin{array}{c}\text { Baseline } \\
\text { LS mean } \\
\text { score } \\
(95 \% \mathrm{Cl})\end{array}$} & \multicolumn{2}{|c|}{ Week 96} & \multicolumn{2}{|c|}{ Week 204} \\
\hline & & $\begin{array}{c}\text { LS mean } \\
\text { score } \\
(95 \% \mathrm{Cl})\end{array}$ & $\begin{array}{c}\text { LS mean } \\
\text { change from } \\
\text { BL }(95 \% \mathrm{Cl})\end{array}$ & $\begin{array}{l}\text { LS mean } \\
\text { score } \\
(95 \% \mathrm{Cl})\end{array}$ & $\begin{array}{l}\text { LS mean } \\
\text { change from } \\
\text { BL }(95 \% \mathrm{CI})\end{array}$ \\
\hline $\operatorname{axSpA}(n=196)$ & $\begin{array}{c}9.47 \\
(7.20-11.73)\end{array}$ & $\begin{array}{c}9.86 \\
(7.52-12.21)\end{array}$ & $\begin{array}{c}0.40 \\
(0.11-0.69)\end{array}$ & $\begin{array}{c}10.08 \\
(7.71-12.46)\end{array}$ & $\begin{array}{c}0.62 \\
(0.22-1.01)\end{array}$ \\
\hline AS $(n=113)$ & $\begin{array}{c}13.17 \\
(9.79-16.56)\end{array}$ & $\begin{array}{c}13.84 \\
(10.35-17.34)\end{array}$ & $\begin{array}{c}0.67 \\
(0.21-1.13)\end{array}$ & $\begin{array}{c}14.16 \\
(10.61-17.71)\end{array}$ & $\begin{array}{c}0.98 \\
(0.34-1.63)\end{array}$ \\
\hline$n r-a x S p A(n=83)$ & $\begin{array}{c}4.42 \\
(2.02-6.82)\end{array}$ & $\begin{array}{c}4.41 \\
(1.97-6.84)\end{array}$ & $\begin{array}{c}-0.01 \\
(-0.19-0.17)\end{array}$ & $\begin{array}{c}4.47 \\
(2.06-6.88)\end{array}$ & $\begin{array}{c}0.06 \\
(-0.17-0.28)\end{array}$ \\
\hline
\end{tabular}

Table B: MRI outcomes to Week 204 of the RAPID-axSpA study for all patients treated with CZP (observed values)

\begin{tabular}{|c|c|c|c|c|c|}
\hline & & Baseline & & Week 204 & \\
\hline & $\mathrm{n}$ & Mean score (SD) & $n$ & Mean score (SD) & $\begin{array}{l}\text { Mean ohange } \\
\text { from } B L \text { (SD) }\end{array}$ \\
\hline SI Joint In & (SPA & & & & \\
\hline $\operatorname{axSpA}$ & 151 & $8.17(13.08)$ & 72 & $1.90(5.00)$ & $-4.70(9.40)$ \\
\hline AS & 91 & $8.50(13.83)$ & 41 & $1.84(5.60)$ & $-4.35(8.49)$ \\
\hline$n r-a x S p A$ & 60 & $7.66(11.93)$ & 31 & $1.97(4.18)$ & $-5.16(10.60)$ \\
\hline Spinal Infla & erlin) & & & & \\
\hline axSpA & 153 & $6.10(8.68)$ & 82 & $2.13(4.46)$ & $-4.84(8.33)$ \\
\hline AS & 92 & $7.38(8.80)$ & 50 & $2.62(5.23)$ & $-5.51(7.61)$ \\
\hline$n r-a x S p A$ & 61 & $4.17(8.21)$ & 32 & $1.36(2.75)$ & $-3.78(9.38)$ \\
\hline
\end{tabular}

Data shown for all CZP-treated patients with valid assessments (including patients re-randomized from PBO at Week 16 or 24). mSASSS: modified Stokes Ankylosing Spondylitis Spine Score; SPARCC Spondyloarthritis Research Consortium of Canada; LS: least squares. SI: sacroiliac 